\title{
Primary extracranial meningioma: A case report
}

\author{
Francisco O. Jiménez-Ascencio, Antonio Herrera-Ortiz, Javier A. Castañeda, Karla L. Luviano-Palmerín, \\ Elba L. Solís Bañuelos, and Yara Y. Ursiel-Ortega
}

Otorhinolaryngology and Head and Neck Surgery Service, Hospital Regional "Dr. Valentín Gómez Farías", Instituto de Seguridad y Servicios Sociales de los Trabajadores del Estado (ISSSTE), Zapopan, Jalisco, Mexico

\begin{abstract}
Extracranial meningiomas are rare and comprise $<2 \%$ of all meningiomas. Only $11.5 \%$ of them are found in the nasal cavity. A case study of a 57-year-old woman is presented with a tumor with extension data through the lamina cribosa, compromising the right nasal cavity and the anterior cranial fossa. Biopsy of the lesion was performed and sent to histopathology, which showed histopathological elements suggestive of meningothelial meningioma. The biopsy was conducted together with neurosurgery, by means of bilateral frontal craniotomy and right lateral rhinotomy, for total resection of the lesion.
\end{abstract}

Key words: Extracranial meningioma. Meningothelial. Primary.

\section{Introduction}

Meningioma is a common tumor that accounts for $13-26 \%$ of all central nervous system (CNS) tumors. Extracranial meningiomas (EM) are rare and comprise $<2 \%$ of all meningiomas and sites such as the spine, nasal cavity, neck, chest, shoulders, and peritoneum have been reported. EM can be subdivided into primary (Protein-energy malnutrition [PEM]) and secondary types, depending on their origin and are referred to as primary independently, and secondary when they show direct communication with the intracranial region. Regarding PEM, only $11.5 \%$ are found in the nasal cavity and the nasal septum ${ }^{1,2}$.

\section{Case study}

A 57-year-old female patient, educator. With genetic predisposition to high blood pressure by both of her parents. Blood type O Rh (+), smoking and drug abused denied, with occasionally alcoholism. A history of direct nasal trauma from a punch, 22 years ago, accompanied by epistaxis, which remitted spontaneously. She attended to the Otorhinolaryngology service for a evaluation due to bilateral nasal obstruction and anosmia. Starting his condition 9 years ago characterized by hyposmia to unspecified odorants which progresses to anosmia, associated to bilateral nasal obstruction of right predominance, with the same evolution time, progressive, which exacerbates in the presence of cold and humid climates, and improves in partial hot climates; These exacerbation episodes are accompanied by whitish rhinorrhea that sometimes turns greenish, non-fetid, coming from the right nasal cavity (RNC), plus constant and progressive posterior nasal discharge of the same characteristics for 5 years. She also refers constant epiphora from the right eye and diplopia of 8 years of evolution, which occurs only when performing eye movements in dextroversion and infraversion. All this associated with

\section{Correspondence:}

*Francisco O. Jiménez-Ascencio

E-mail: omar_jias@hotmail.com

DOI: 10.24875/HGMX.20000040
Date of reception: 05-03-2020

Date of acceptance: 30-04-2020
Available online: 12-11-2020

Rev Med Hosp Gen Mex. 2020;83(4):172-175 www.hospitalgeneral.mx NC-ND license (http://creativecommons.org/licenses/by-nc-nd/4.0/). 


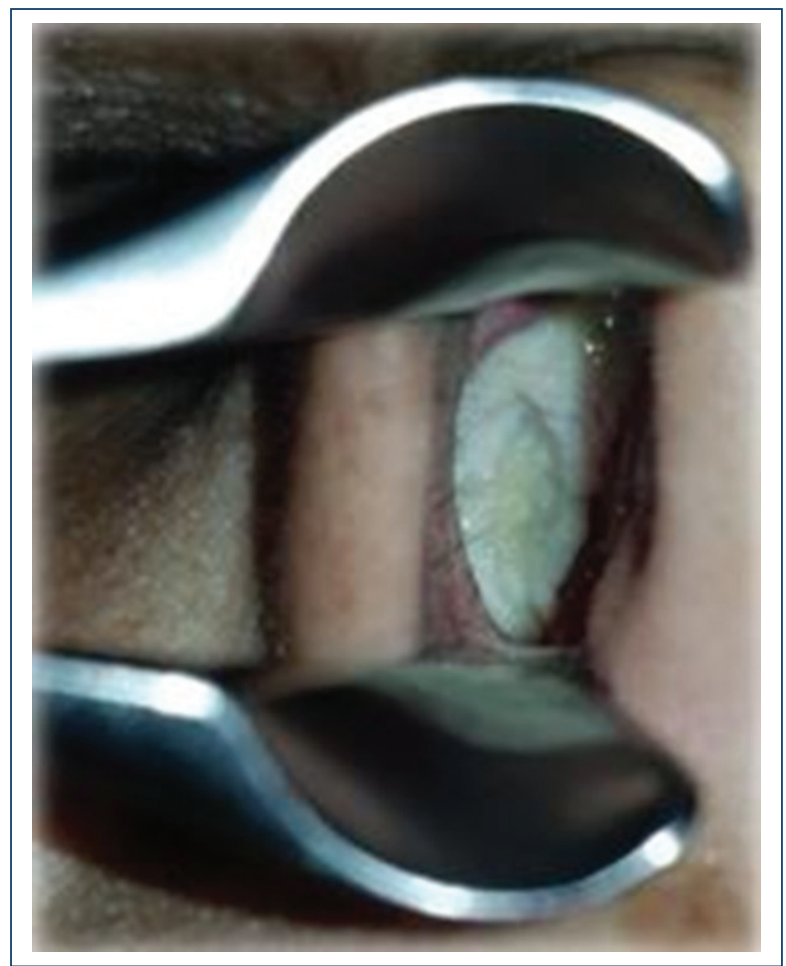

Figure 1. Anterior rhinoscopy of the right nasal cavity.

intermittent holocranial headache, oppressive type, moderate to intense, VAS 5/10, which is attenuated with conventional analgesics (paracetamol, ibuprofen, among others).

On physical examination, the patient was found to have a mesorrhine nose, with crepitus of the nasal pyramid on palpation in the upper right part. Rigid nasal sinus endoscopy was performed at $30^{\circ}$, finding eucromic, and hydrated mucosa. A nasal tumor was visualized on the RNC that occupied $90 \%$ of the cavity, with a polypoid appearance, greyish color, irregular, non-ulcerated surface, friable, and partially fixed that does not get pale with pressure, but is slightly painful (Fig. 1). Permeable left nasal cavity, functional septum, and no signs of lesions were visible.

A neurological assessment of the patient's mental functions was carried out, where a memory deficit in the evocation phase was identified, being complemented with neuropsychological tests. An exploration of the cranial nerves detected:

I - Bilateral anosmia.

II - Isocoric pupils, photomotor, and consensual reflex without alterations.

III, IV, and VI - Extraocular movements without alterations.

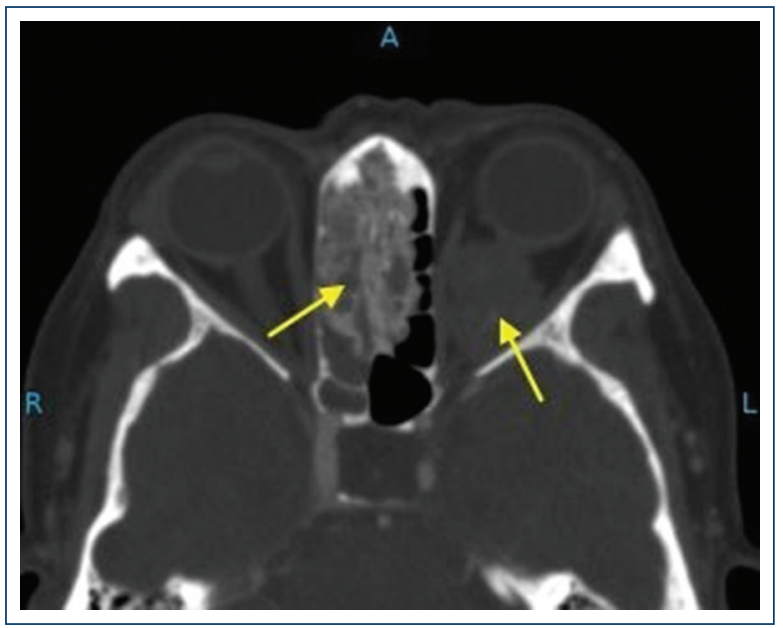

Figure 2. Axial computed tomography scan showing erosion and hyperostosis at the level of the lamina cribosa of the ethmoid and left intraconal lesion.

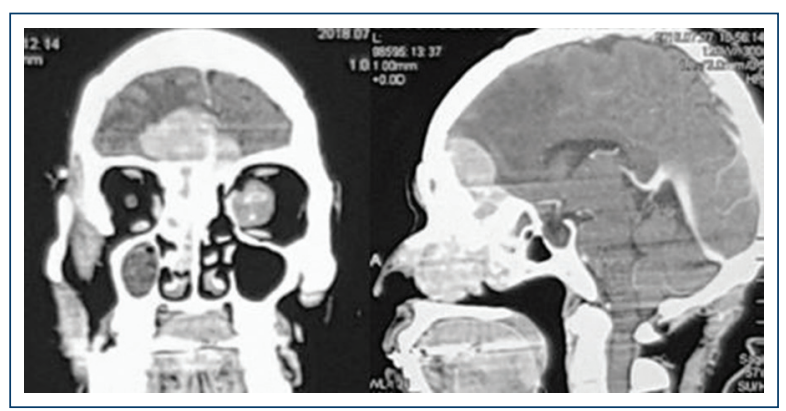

Figure 3. Axial and sagittal computed tomography scan, which denotes an avid enhancement of the lesion to the contrast agent and partial lesion.

V - Preserved facial sensitivity, branches V1, V2, and V3 without alterations.

VII - Symmetrical facial expression.

No other significant alterations.

The patient was referred for a head and face-computed tomography (CT) scan with a contrast agent, where we could observe a lesion that occupies almost the entirety of the RNC and the frontonasal midline area, slightly hyper-dense at the soft tissues of the brain, well defined, with irregular edges, generating erosion, and hyperostosis around the lamina cribosa of the ethmoid and part of the frontal bone (Figs. 2 and 3).

In addition, an isodense lesion similar to a soft tissue lesion is observed, located in the left orbital cavity (intraconal), well defined, with regular borders and homogeneous content, with some hyperdense foci similar to bone tissue, generating displacement of the extraocular 


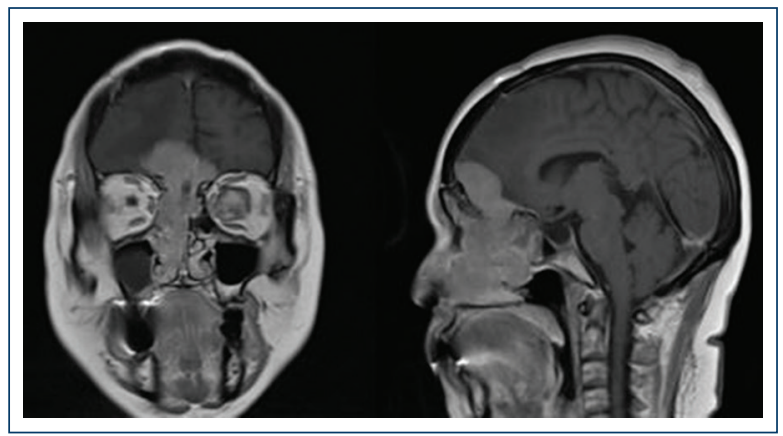

Figure 4. Coronal and sagittal $\mathrm{T} 1+\mathrm{C}$ magnetic resonance imaging scan showing visible enhancement of the lesion.

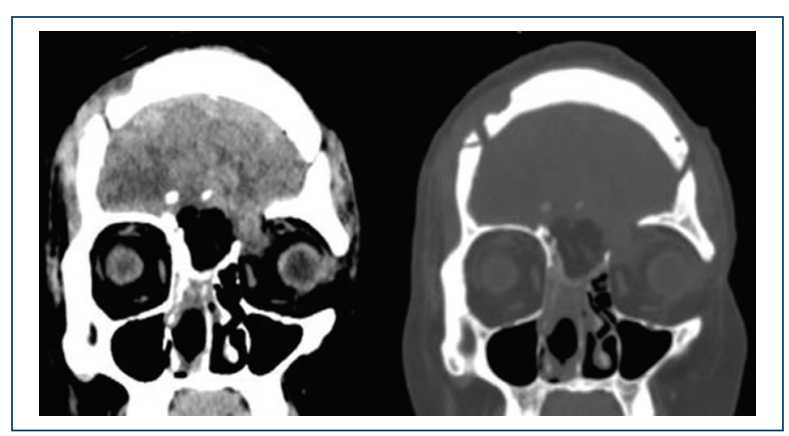

Figure 5. Post-surgical soft tissue and bone coronal computed tomography scan.

muscles: medial and lateral rectus. Without producing alterations at the bone level or other adjacent tissues (Fig. 2).

The case study was complemented with a magnetic resonance imaging (MRI) scan, where a space-occupying lesion was observed. It showed extension data through the lamina cribosa compromising the RNC and the anterior fossae bilaterally and predominantly solid, with a signal similar to that of the grey substance in the T1 sequence, and in T2 sequence, as well as avid enhancement in the T1 sequence after the administration of gadolinium (Fig. 4).

In the orbital region on the left side, there was an occupying lesion in the intraconal compartment, located in the middle third for the orbital path of the optic nerve sheath, showing a fusiform morphology, with smooth margins and heterogeneous enhancement after the administration of gadolinium.

The lesion was biopsied at an outpatient unit by an endoscopic nasal approach and sent to histopathology for analysis, where histopathological elements of meningothelial meningioma were reported.
The following procedure was performed jointly at the neurosurgery service: right lateral rhinotomy for total resection of the lesion and bilateral craniotomy (bi-temporal approach), with the left orbit exploration and biopsy (Fig. 5), which was sent to histopathology and was diagnosed as meningothelial meningioma.

The defective areas were sealed with absorbable collagen implants, abdominal fat, and physiological fibrin adhesive.

Two years after the surgery, the patient is free of disease, persisting only with memory deficits in the evocation phase and bilateral anosmia.

\section{Discussion}

Meningiomas are slow-growing, benign tumors, usually intracranial, and account for $13 \%-26 \%$ of all CNS tumors. They usually appear between the fourth and sixth decades of life, are rare in children and clearly predominant in women ( $75 \%$ of cases). The extracranial location represents $1-2 \%$ of all these tumors and has been described more frequently in males and young adults. They are considered primary, when they originate independently and secondary, when they are directly related to the intracranial region. Most EM are secondary, as up to $20 \%$ of intracranial ones have extracranial extension. Histologically speaking, primary EM does not differ from intracranial ones. Most of these tumors are sporadic, and their etiology is unclear. In very specific cases, a possible cause can be identified, such as radiation exposure, type II neurofibromatosis, chromosome 22 abnormalities, exposure to adenovirus type viruses, and hormonal factors. There are various hypotheses about its origin, which stem from arachnoid cells of the cranial nerves or from ectopic meningocytes (arachnoid cap cells). In general, the most common symptoms and signs of sinus meningiomas can mimic a condition of sinusitis with nasal obstruction, anosmia, facial pressure or pain, epistaxis, and rhinorrhea. In $10 \%$ of cases, they may remain asymptomatic even in advanced stages. The clinical examination should be thorough and include nasal endoscopy, which usually shows a firm, pink to grey in color, globular, or lobular but well-circumscribed mass, with displacement but not infiltration of the surrounding tissue. The differential diagnosis must be made with mucocele, olfactory neuroblastoma, carcinoma, hemangio$\mathrm{ma}$, sarcoma, and angiofibroma ${ }^{3,4}$. Therefore, histology is essential, and for clinical purposes, four patterns are described: syncytial or meningothelial, fibroblastic, transitional, and angioblastic. Most primary extracranial 
sinus meningiomas are meningothelial. Immunohistochemistry is useful to confirm the diagnosis. Thus, these tumors usually show strong positivity to vimentin and epithelial membrane antigen and are focal positive for s-100, keratin, and carcinoembryonic antigen ${ }^{5}$. Both CT and MRI scans are essential in pre-operative surgical planning. Surgical removal is the first option for treating PEMs in the head, which can achieve the dual objective of confirmed diagnosis and treatment of tumors. If possible, both the tumor and all the tissues involved should be completely resected, followed by reconstruction of the defects. Radiotherapy should be reserved for a palliative approach ${ }^{6,7}$. Total surgical resection of the lesion can be carried out by endoscopy, open surgery, or a combination of both ${ }^{8}$. The rate of recurrence varies according to histological subtypes, with a worse prognosis for the angioblastic variant because resection is more difficult ${ }^{9,10}$.

In our case study, there was no recurrence in the subsequent 24-month follow-up. Recurrence usually occurs at the same anatomical site as the primary lesion and, depending on the time interval, can be distinguished from residual disease. A study analyzing the relationships between tumor sites and recurrence and death in 170 cases has found statistically significant differences between recurrence and type of resection. They found recurrence rates of $9.7 \%, 14.3 \%$, and $66.7 \%$ in cases of the total, subtotal, and partial resection, respectively. Furthermore, they found mortality rates of $5.4 \%$ and $28.6 \%$ in cases of total and subtotal resection, respectively. A 5-year disease-free survival rate of $66.9-82.1 \%$ was found, in addition to a 10 -year disease-free survival rate of $54.6-78.6 \%{ }^{11}$.

It is important to have a high index of suspicion for rare tumors in the nasal cavity and sinuses to reach a diagnosis. The usefulness of MRI scans in the diagnosis of extracranial head and neck tumors is highlighted, as well as common differential diagnoses. Although there is no agreement on their management, as they require individualized treatment, surgical resection is the primary treatment option, together with close follow-up to assess cases of residual disease.

\section{Acknowledgments}

The author would like thank to Dr. Antonio Herrera Ortiz, Professor and Head of the Department of Otorhinolaryngology and Head and Neck Surgery at the "Dr. Valentín Gómez Farías" Regional Hospital, for the use of the research facilities and clinical contribution and to thank Dr. Jorge Enrique Chávez Navarro, for the critical review of the manuscript.

\section{Conflicts of interest}

The authors declare that they have no conflicts of interest.

\section{Ethical disclosures}

Protection of human and animal subjects. The authors declare that the procedures followed were in accordance with the regulations of the relevant clinical research ethics committee and with those of the Code of Ethics of the World Medical Association (Declaration of Helsinki).

Confidentiality of data. The authors declare that they have followed the protocols of their work center on the publication of patient data.

Right to privacy and informed consent. The authors have obtained the written informed consent of the patients or subjects mentioned in the article. The corresponding author is in possession of this document.

\section{References}

1. Flint PW, Haughey BH, Niparko JK, Richardson MA, Lund VJ, Robbins KT, et al. Cummings Otolaryngology-head and Neck Surgery. Philadelphia, PA, USA: Elsevier Health Sciences; 2010.

2. Arias-Marzán F, de-Lucas-Carmona G, Álvarez-Flórez M, Febles-García $P$. Meningioma primario extracraneal de senos paranasales. Acta Otorrinol ESP. 2009;61:238-40.

3. Harnsberger HR, Glastonbury MC, Michel AM, Koch LB. Diagnóstico por Imagen Cabeza y Cuello. Madrid, España, Marbán: Rústica; 2013.

4. Johnson JT, Rosen CA. Baileys Head and Neck Surgery: otoryngology. Philadelphia, PA, USA: Lippincott Williams \& Wilkins Company; 2013.

5. Ghosh A, Ghartimagar G, Thapa S, Shrestha MK, Talwar OP. Primary nasal meningioma-a case report. J Pathol Nepal. 2017;7:1127-9.

6. Mattox A, Hughes B, Oleson J, Reardon D, McLendon R, Adamson C. Treatment recommendations for primary extradural meningiomas. Cáncer. 2011;117:24-38.

7. Bassiouni H, Asgari S, Hübschen U, König HJ, Stolke D. Participación dural en meningiomas extradurales primarios de la bóveda craneal. $J$ Neurosurg. 2006;105:51-9.

8. Jiang RS, Chang KM, Hsu CY. Endoscopic sinus surgery forethmoid sinus meningioma. Zhonghua Yi Xue Za Zhi. 2000;63:158-61.

9. García-Purriños FJ, Rosell-Cervilla A, Lemberg P, Calvo-Moya J. Nasal malignant meningioma. Acta Otorrinolaringol. 2005;56:373-5.

10. Thompson LD, Gyure KA. Extracranial sinonasal tract menin-giomas. Am J Surg Pathol. 2000;24:640-50.

11. Liu $Y$, Wang $H$, Shao $H$, Wang $C$. Primary extradural meningiomas in head: a report of 19 cases and review of literature. Int J Clin Exp Pathol. 2015;8:5624-32. 